\title{
The Forgotten Third: A Comparison of China, US, and the European Union's Al Development
}

\author{
Theo Abramo ${ }^{1}$ and Emma Campbell-Mohn\# \\ 'Jumeirah English Speaking School, Dubai, UAE \\ \#Advisor
}

\section{$\underline{\text { ABSTRACT }}$}

In the $21^{\text {st }}$ century, great power competition dominates the field of international relations. Much has been written about the US and China rivalry for technological dominance, specifically in artificial intelligence. But these analyses are missing one essential player: Europe. I ask will China use its advancements in artificial intelligence to overtake the United States as a superpower, disrupting the US hegemon, just as the United States once did in a post-cold war era with the USSR. Europe is developing its own strategy and capabilities to rival those of the US and China. I use a cross-country qualitative case study method to examine advancements in artificial intelligence across the US, China, and Europe, specifically France and Germany. To determine each states' leadership and capabilities, I compare them across their AI dreams, hardware, research, and ecosystem. In this comparison I find that whilst China's numbers outcompete the US and Europe in total output, there are multiple criterium, notably in top tier development, where there is still a significant gap China needs to close between its rivals. Thus, providing an opportunity for Europe, specifically France and Germany, to develop and lead certain criterium regarding core AI development. This paper contributes to existing scholarship on artificial intelligence and US-China relations by adding the European dimension.

\section{Introduction}

Artificial intelligence with the rapid increase in Chinese influence and the unexpected rise of the EU will threaten the USA's world order, thus weaking it as a superpower.

Since the Cold War ended with the defeat of the USSR in 1991, US influence has dominated international systems. This has often been referred to as a "unipolar" moment in history (Krauthammer, 1990).

Post-World War II (WWII) reconstruction and the Cold War played a crucial role in defining USA's position on an international stage. The Cold War was a battle between two key superpowers, the USA and the Soviet Union. Following the devastation of WWII and the end of the Cold War the United States played a key role in stabilizing Europe notably in the economic, political and military spheres (van Heuven, 1993). Whilst the United States experienced exponential economic growth, it also created guidelines in terms of international leadership like the development of the Marshall Plan and the North Atlantic Treaty Organization (NATO), all of whom played an important role in the development of Europe.

At the same time, America was leading the world in the third industrial revolution, which included mainframe computing, personal computing and the internet which are the primary reasons for its rapid economic growth. The post-cold war era and the fall of the USSR left the United States with unexpected inherited unipolarity, that further expanded due to its significant advancements in the fields of technology (Wohlforth, 1999). In this unipolar moment, the US lead a world order based on principles of economic and political liberalism, a commitment to global open markets and the promotion of 'free market democracies' (Apeldoorn \& Graaff, 2015). "With Moscow's headlong fall from superpower status, the bipolar structure that had shaped the security policies of the major powers for nearly half a century vanished, and the United States emerged as the sole surviving superpower" (Wohlforth, 1999). This inherited order, re-enforced by American hegemony, was left temporarily unchallenged. 
Yet, this order is not unchallenged. The recent Chinese 'takeoff'(Huang, 2012) since late 1970s and remarkable development in leading industries shaping a path to exponential economic growth has increasingly gained relevance on an international stage, threatening USA's established liberal world order and unique position as leader in international politics. This has raised one pertinent question amongst academics and researchers, due to China's reemergence as a superpower and significant advancements in AI and related technologies, will China use the inevitable fourth industrial revolution to overtake the United States as a superpower, disrupting the rules and hegemon it has formed, just as the US once did in a post-cold war era? What does this mean for the distribution of global power?

The current debates on US-China asserting world dominance are missing one essential element: Europe. In this article, I formulate an argument on why it is essential to include Europe in this conversation. Whilst it's true that the US will long remain to be a superpower as its "market power is still unparalleled and underpinned by the dollar's status as the unrivalled global reserve currency" (Routledge, 2015); China does represent an emerging threat in distribution of power - with the ability to challenge the US status as leading country in the next era of artificial intelligence and related technologies.

Artificial intelligence (thereafter AI) is the driving force of a new round industrial revolution that will cause significant changes in social efficiency, economic growth, and national security. The AI race is a multisectoral race affecting every industry, throughout this journal I present an analysis on the US's, China's, and Europe's, specifically France and Germany, AI advancements and the pivotal role this plays in shaping the future of international politics. Moreover, by dissecting EU-US-China tripartite relationship, I formulate arguments on why it is essential for the European Commission to articulate a clear, unified AI vision centered around developing, a strong ecosystem - ensuring AI doesn't become a source of indifference within Europe

\section{Review of Literature}

\section{What is Artificial Intelligence?}

Currently AI has been misperceived as extremely futuristic technology that is unobtainable. Due to the vague "visionary' description of this concept, there are room for various interpretation and analogies from the most far-fetched fiction books to academics drawing parallels to their specific discipline. As these approaches developed alongside AI advancements, the perception of the general technology depicts a flawed image of what AI is and can be. What few understand is that $\mathrm{AI}$ is not new: it is mostly based on algorithms developed from pre-existing knowledge from the '60s and '70's.

In order to understand how AI effects, the balance of power and Europe's role, a definition is required; however, defining AI is no easy task. Artificial Intelligence was first coined in 1956 by McCarthy - often referred to as one of the 'founding fathers' of this technology. He defined it as the science and engineering of making intelligent machines, especially intelligent computer programs (McCarthy, 2007). However, as AI evolved, creeping into every sector, the approaches to defining this concept became ever so different. Fundamentally, it refers to a program whose ambitious objective is to understand and reproduce human cognition; creating cognitive processes comparable to those found in human beings (Meurier, 2018). The main reason why this concept has become so relevant in the $20^{\text {th }}$ century is due to two vital innovations that are predominantly responsible for AI entering a new era, an era of: machine learning $^{1}$ and deep learning ${ }^{2}$ (both of which are subsets of AI). Whilst this paper is focuses on the political implication of this technology it is worth noting that AI advancements have impacted almost every industry from health and transport to development of robots and blockchain due to drastic increases in computing power and the rapid digitalization of

\footnotetext{
${ }^{1}$ Machine learning uses algorithms to interpret vast amounts of data, learn from that data and make informed decision based the information gathered

${ }^{2}$ Deep learning is technically a subset of AI that layer's structures of algorithms to create an "artificial neural network" that can learn and make decisions independently.
} 
our world. AI has the potential to disrupt every sector of our economy as well as completely change our way of life. Given the extent of the disruption that analysts believe AI could cause in the global economy, it is worth associated AI in the context of other major technological changes like the industrial revolutions (Horowitz, 2018).

As our society progresses and evolves there has been three fundamental occasions from 1760s to 1950s that catalyzed a shift into a new era which completely transformed our modern society, referred to as the industrial revolutions. Past industrial revolutions have generated significant changes in the balance of power, international competition, and international conflict (Horowitz et al., 2018). Similarly, future revolutions will have the power to disrupt every sector and generate, once again, significant changes in international relations.

The first industrial revolution originated in Britain in the $18^{\text {th }}$ century, after the invention of the steam engine and mass production of goods and products generating huge increases in productivity. The changes created were not only in technology but also in lifestyle. This changed traditional family life revolving around rural living and farming to factory life in the bustling cities with poor working conditions and low wages. Moreover, Great Britain being the epicenter of this revolution witnessed a great shift in the balance of power, becoming the leading power in Europe and on international stage. Hence, this competitive edge fueled the growth of the British empire and created a gap with the rest of the world that took decades to close.

The second industrial revolution - often referred to as the technological revolution - occurred from the late $19^{\text {th }}$ century to early $20^{\text {th }}$ century and renewed international competition. Bringing about the invention of new energy sources combined with the development of telephones, computing, automobiles, and machinery leading to a rise in automation. Whilst there was no distinct country at the origin of this revolution, the leading countries were: Britain, France, and Germany competing in Europe along the rising United States and Japan. Nations were competing on a global scene in the harvesting of steel production, electricity, and petroleum. The rising tensions between nations and the race to lead this multipolar environment fueled the escalation of the trench warfare, WWI. Completely reshaping warfare with the creation of tanks, trucks, radios, etc. that were perfected during WWII.

Finally, in 1950 onwards we advance to a third industrial revolution also known as, the digital transformation, that completed changed the playing field. With the combination of transistors, microprocessors, global production chains and electronics, produced a wave of innovation that, once again, increased international competition. A wave that created the internet, GPS, 3D printing and various other technologies that act as a backbone to our modern society. Unlike, the previous industrial revolutions, the digital shift was led by American power, with companies such as Google or Apple - monopolizing the internet from the software to the hardware. Rather than leading an intense international competition, this revolution allowed the United States to further widen the gap and project power - establishing its position as world leader (Hoppe \& Bhagat, 2007).

As the famous speculative-writer, William Gibson said: "the future is already here - it's just not very evenly distributed". The overall impact of these industrial revolutions on the distribution of power was dependent on not just the advancement of these technologies as such, but more how companies and governments were able to adapt and use these technologies to become more efficient and consistent. Alternatively, technologies that forced companies to face an 'adapt or die' approach, tend to be more disruptive. Thus, it is essential for countries to formulate a coordinated response to $\mathrm{AI}$ and ensure a strong collaboration between the private and public sector, in aim to encourage industries to transition and develop AI technologies.

The increasing role emerging technologies play in our daily life will give rise to a new movement, that will once again lead to "a series of significant shifts in the way that economic, political and social values are being created, exchanged and distributed" (Philbeck \& Davis, 2019) testing the ability for governments and firms to adapt and evolve. The arrival of the digital revolution in 1980 laid the groundwork to this 'fourth industrial revolution' - powered by robotics, the Internet of Things (IoT), 5G infrastructure, nanotechnology, biotechnology, quantum computing and AI amongst others - amplifying each other in the fusion of technologies across the physical, digital, and biological realms. AI technology is one of the few technologies that can revolutionize every industry and society, however, is reliant on vast amounts of data and research to develop. Hence, understanding the relationship between the three major players 
in global politics US-China-EU, is essential to formulate an argument to who is going to be the leader of the fourth industrial revolution.

The concept of the fourth industrial revolution was first referred to as 'Industry 4.0' initiative that emerged in 2011 where three representatives from the spheres of science, politics and business were assigned to develop a hightech strategy for the German government (Kagermann et al., 2013). In which, they described "how the paradigm shift will take place in industry" and how "in the next decade, new business models based on cyber-physical systems will become possible". This government initiative also referred to as I4.0 was originally designed to promote computerization of manufacturing through a set of implementation recommendations to the German federal government (Federal Ministry of Education and Research, n.d.). These recommendations rested on the improvement of automation technology by introducing digital business models, standardization, new technology and research, legal framework, and security of networked systems (Messe, 2019). This term was further developed by academics and professors like, Klaus Schwab, as 'the Fourth Industrial Revolution', where he describes this hyperconnectivity between the physical, digital, and biological spheres as, "nothing less than a transformation of humankind" (Schwab, 2017). The development of hyper automation and the fusion of technologies powered by AI will once again catalyze a shift in a new era, completely transforming the way society behaves, generating significant changes in the balance of power and international relations and cooperation. In contrast to past industrial revolutions, this fusion of technologies will impact every sector, automating and augmenting a broad range of tasks, bringing important "technical and ethical challenges to sectors, stakeholder groups, and social norms" (Philbeck \& Davis, 2019).

Thus, the importance of the fourth industrial revolution shouldn't be analyzed in terms of technological advancements of individual countries but their flexibility to change and adapt to these advancements and the impact this will have on the global order. Whilst it's true we are entering an era of exponential economic growth, we are also entering an era of great power competition, characterized by "struggle, change, competition, the use of force, and the organization of national resources to enhance state power". Industrial productivity, science, and technology are critical in this struggle as well, notes international relations scholar Paul Kennedy (1988).

AI's growing presence plays a vital role in shaping state power, especially as the leading country in this 4IR will also "emerge as the driving force in defining ethical norms and standards [for AI]". Thus, given the nature of AI and the vast differences in values between the US, China, and Europe, it is essential for the EU to formulate a clear strategy to lead the 4IR - reaffirming its seat as the leading industrial region.

\section{Methodology}

To compare the AI developments of the US, China, and the EU focusing specifically on France, and Germany I will be using both a qualitative and quantitative methodology.

Due to AI's 'omni-use' potential the thin line between core AI technologies and AI related technologies is often blurred, so how each country interprets the difference between the two is essential to formulate an accurate comparison. The clearest way to assessing a country's AI vision and advancements is first done by understanding its 'AI dreams'. I will commence by analyzing each nation's goals and strategies implemented by comparing, through governmental documents, each regions objectives outlined for the coming years. Then, to get a sense their current AI strengths and capabilities, I will be using some of the core categories articulated by Jeffrey Ding notably in AI hardware, AI research and development (AI R\&D) and strength of AI ecosystem (2018). I have chosen these three categories from Ding's research as they are crucial to formulating, as later explained, a macro-perspective on the development of AI technology as a whole.

Advancements in AI hardware is imperative to become leader in this sector as not only will it mean complete autonomously in the creation of AI chips, a necessity for supporting AI algorithms, but will also facilitate the development of faster and more efficient cutting-edge systems. Thus, by analyzing the global market share of semiconductor production, the highest performing supercomputers, the number of firms developing AI-specific chips and the overall investment in this market I will be able to construct an overall image of each nations raw processing power. 
Then, AI R\&D provides the necessity framework to determine a nations potential in terms of innovation and capabilities. By further dissecting this section, I will be able to compare each state's potential, thus competitiveness on an international stage. Some of the sections I will be analyzing include: the general paper output and influence in AI related research, the number of AI patent, and the number of AI talent - for both firms and countries.

Finally, for a nation to fully benefit from its vision, hardware, and R\&D it must first and foremost develop a strong AI ecosystem. Thereby, by understanding the difference in AI ecosystem of each region through primarily focusing on the funding and number of AI startups, a comparison can be made between China, the US and the EU in terms of their talent and foundations for AI.

Through a cross-country qualitative case study method, I will use these four categories to examine advancements in AI across the US, China, and Europe, specifically France and Germany. This report draws upon specialized databases to understand the current state of the AI industry notably in AI output (journals, patents, and talent), AI specialists and policy documents. The data collected draws upon various reliable sources from both previous academic research conducted and databases.

\section{Comparing AI dreams}

\section{Understanding China's AI Dream}

In 2017, China's president Xi Jinping outlined his vision for China becoming a global science and innovation leader by 2050. The government has been paving the way for years and the country's knowledge-intensive high-tech sectors has been developing at a rapid pace.

In the $19^{\text {th }}$ Party Congress in October 2017, China's General Secretary of the Chinese Communist Party Xi Jinping outlined his vision for China's advancements and his aspiration for China to be "a leading nation in terms of national power and global impact by 2050" (Roberts et al., 2021) notably regarding "propelling China into a leading position in terms of economic and technological strength" (Jinping, 2017). Development in AI has become fundamental for realizing this goal. A clear turning point in China's AI views that led to such important initiatives to developing this technology was in March 2016 with the victory of Google DeepMind's AlphaGo (a computer program) on Lee Sedol, winner of 19 world titles, 4-1 (Li \& Ruiyang, 2016). The victory of the computer algorithm played a vital role regarding China's views on AI and acted as a sort of 'sputnik moment' for China and "the event paved the way for a new flow of funds into the discipline" commented the two professors who consulted with the government on their AI strategy (Mozur, 2017). In July 2017, The State Council of China released the 'New Generation Artificial Intelligence Development Plan' that officially outlined 3 strategic objectives, making China's growth in the AI sector a "national priority". These objectives are: (1) by 2020, China will have actualized important progress in the spheres of AI and AI related technology - with aspirations to make China the world's primary AI innovation center cultivating leading AI 'backbone enterprises' with an AI core industry scale exceeding RMB 150 billion, and of related industries exceeding RMB 1 trillion; further developing its AI ecosystem as well as developing AI ethical norms. (2) By 2025, China aspires to develop "major breakthroughs in basic theories for AI" as well as have official legal frameworks established for AI laws. (3) By 2030, China dreams of becoming the major hub for AI innovation and development with the AI core industry exceeding RMB 1 trillion and related industries exceeding RMB 10 trillion (Graham Webster et al., 2017). Whilst this plan does represent an important milestone for China, it is only a small part of its overall AI strategy, merely acting as a continuation of previous government initiatives like the ' $14^{\text {th }}$ Five-Year Plan' or the 'Made in China 2025 Industrial Plan'. As well as, in the past, academics and researchers have assumed that China's approaches to AI were defined by its "coherent top-down geopolitically driven national strategy, reflecting Chinese leaders' global ambitions" (Zeng, 2021). With China being a re-emerging global superpower it is home to $23 \%$ of AI companies (Lam et al., 2019) - like Tencent, Alibaba, and Baidu - the central government does play an important 
guiding role in AI advancements however is not the sole contributor. As scholars like Jinghan Zeng argue, instead of a top-down approach, China's government dictates the overarching goals and is simply designed to help bureaucratic agencies, private companies, academic labs, and subnational governments to achieve their own interests, thus also allowing businesses to adopt, through its flexibility, a bottom-up approach (Zeng, 2021).

\section{Understanding the US's AI Dream}

In February 2019, the Trump Administration signed Executive Order (EO) 13859, Maintaining American Leadership in Artificial Intelligence, announcing a nationwide plan for developing AI. This launched the American AI Initiative, identifying USA's long-term vision for AI development under five major strategies (Kratsios \& Parker, 2020) that were later codified into laws as part of the National AI Initiative Act of 2020. The EO aims to "ensure that technical standards (...) reflect Federal priorities for innovation, public trust, and public confidence in systems that use AI technologies (...) and develop international standards to promote and protect those priorities". These AI strategies as per the EO include (1) driving technological breakthroughs, (2) developing appropriate technical standards, (3) training the current and future generation of American workers, (4) foster public trust and confidence, and (5) promote an international environment supporting American AI research and innovation (Trump, 2019). In support of this initiative, the Select Committee released an updated version of the 2016 National AI R\&D Strategic Plan; accounting for new research and innovations, it outlined eight clear strategic priorities to guide federally funded AI research. According to the 2020 Budget for a 'Better America', it provides USD 688 million for the National Institute of Standards and Technology (NITDR) to "conduct cutting-edge research, including quantum computing, artificial intelligence, and microelectronics" (Kratsios, 2019). Later, the NITDR also released a Supplement Report to the President's FY2020 Budget showing a breakdown of the first agency-by-agency budget allocation for non-defense AI R\&D, equating to nearly USD 1 billion for the year (White House, 2020). The document also provides an important baseline that outlines key programs and the administration's strategic priorities, making AI - along with quantum information sciences and strategic computing - the second highest R\&D priority behind national security. In addition to USD 1 billion pledged by the US government, starting from 2019 fiscal year, the Defense Advanced Research Projects Agency (DARPA) plans to add an additional USD 2 billion over the next 5 years in "new existing programs called the 'AI Next' campaign". This campaign aims to bring about a 'third wave' of AI technologies where "systems are capable of acquiring new knowledge through generative contextual and explanatory models" (DARPA, 2019). Whilst the US government does play a role in the development of AI, it has over the years adopted a bottom-up approach with private companies leading the growth of AI. It is important to consider, government spending represents a small portion of total investments, with the tech giants like Nvidia, Alphabet and Amazon paving the road for AI investments. As a report from CSET argues, major AI companies are often categorized together as general AI leaders, however, focus on very different subfields within AI with "considerable differentiation in the areas of research they prioritize in". Essentially, positioning the US government as a 'gap filler' in research that is underinvested by the private sector (Gelles et al., 2021).

\section{Understanding the EU's AI Dream}

In 2018, the European Council formulated a Declaration of Cooperation on AI, signed by 25 European member states (including the UK). Whilst some of these countries, mainly the west, already have announced their own AI initiatives it is essential for the EU to formulate a coordinated approach to increase its competitiveness with major powers like the US and China as well as to ensure that 'European values' are upheld. This coordinated approach aimed to (1) ensure Europe is competitive in the AI landscape, (2) guarantee all countries adapt in this digital transformation, and (3) develop new technologies in accordance with its values. Moreover, in February 2020, the European Commission published a White Paper on AI which proposes policy options on how to achieve the "twin objective of promoting the uptake of AI and of addressing the risks associated with certain uses of this new technology". In cooperation with both 
national and private sector, the EU's holistic approach aims "to increase investment and reach a total of at least EUR 20 billion" (European Commission, 2020). The EU is also actively promoting research and innovation whilst safeguarding ethical aspects of the progress achieved regulated by the EC-appointed High-Level Expert Group on AI (European Commission, 2019). As argued by scholars like Fabien Merz, the EU has created an 'umbrella approach' where it aims to maintain global competitiveness in AI and create the conditions to closing the gap between the US and China whilst simultaneously developing corresponding regulatory and ethical guidelines. France and Germany are arguably two of the most advanced countries in AI within the EU however have two distinct strategies.

\section{Understanding Germany's AI Dream}

In November 2018, the Federal Government of Germany launched like France an AI Strategy, that presented the progress made, goals for the future and policy initiatives to be done in Germany. The strategy is revolved around three main goals: (1) increasing and consolidating Germany's future competitiveness by making Germany and Europe a leading center in AI, (2) guaranteeing a responsible development and deployment of AI which serves the good of society, and (3) integrating AI in society in ethical, legal, cultural, and institutional terms in the context of a broad societal dialogue and active political measures. The FY2019 Budget has allocated a total of EUR 500 million to 'beef up' the AI strategy for 2019 and pledged by 2025 to provide around EUR 3 billion for the implementation of the strategy (Federal Republic of Germany, 2020). Of the EUR 500 million budgeted in 2019, EUR 190 million was invested in research and education in AI. As well as some of the key projects it announced were to create at least 100 additional professorships for AI to ensure its presence in higher education system as well as establish a 'teach-andlearn AI' platform dedicated to developing the necessary skills to understand, thus, operate AI. Moreover, in response to the AI talent shortage, the Federal Government also launched large scale qualification initiatives revolved around 'upskilling' and 'reskilling' workers across any industry to make them more future ready (Federal Ministry of Education and Research et al., 2018). Moreover, Germany announced numerous partnerships both locally and nationally, like the Franco-German research and development network to ensure cooperation in AI research and innovation. Similarly, to France, the report also focuses on "integrating AI in society in ethical, legal, cultural and institutional terms" through developing joint guidelines with businesses and AI dedicated platforms.

\section{Understanding France's AI Dream}

The report written by mathematician and member of parliament Cedric Villani in 2018 subtitled 'Towards a French and European Strategy' announced France's AI ambition to "playing a leading role at [a] global level and compete with non-European giants [in AI]", heavily relying on research and innovation (Meurier et al., n.d.). The Mission Villani report essentially addresses seven main objectives, which are to: (1) develop an aggressive data policy, (2) target the 'four strategic' sectors (healthcare, environment, transport, and defense), (3) boost the potential of French research, (4) plan for the impact of AI on labor, (5) make AI more environmentally friendly, (6) open up AI black boxes $^{3}$, and (7) ensure that AI supports inclusivity and diversity. According to the European Commission the French government will dedicate EUR 1.5 billion to the development of AI by the end of 2022, including EUR 700 million for research. Some of the key issues that France's faces regarding AI development is the 'endemic' brain drain of researchers towards the major industrial players "GAFAM and other unicorns" due to its weak AI ecosystem which then results in significant knock-on effects regarding competitiveness for AI talent. Thus, one of the main focuses of the French AI strategy highlighted by Emmanuel Macron, the French president, is "to improve the AI education training and ecosystem to develop and attract the best AI talent" (European Commission, 2021). In coordination with

\footnotetext{
${ }^{3}$ In machine learning, AI black boxes are systems whose inputs and operations are not visible by the user or creator and are created directly by the algorithm from the data to calculate predictions. Models are creating where even those who design them are unable to understand how variables are being combined to make predictions.
} 
leading research entities and universities, the National Research Institute for Computer Science and Automatism (INRIA) oversees the main strategies proposed. One of the two flagship projects suggested by Villani is the establishment of interdisciplinary institution on AI (known as 3AI) across France, which essentially creates a network designed to strengthen the AI sector and enhance research and innovation amongst institutions involved in AI research. As well another of Villani's flagship projects is the creation of an Ethics Advisory Committee for Digital Technologies and AI to oversee AI developments. Essentially these two initiatives will 'encourage' AI development that is environmental and ethical; through collaborations and immediate access to cutting-edge AI research for France and partnered countries (Villani, 2018). By promoting collaborative research agreements between renowned research institutions notably with the trilateral French-Japanese-German research projects on AI in partnerships with: the French National Research Agency (ANR), the German Research Foundation (DFG), and the Japan Science and Technology Agency (JST); will as outlined by the European Commission create a network that will allow "for an efficient sharing of knowledge associated with AI across various stakeholders and increases their motivation to participate in cutting-edge AI research" (European Commission, 2021). France has also created a National Commission for Information Technology and Liberties (CNIL) which developed a Digital Republic Bill that outlined characteristics that must be "at the heart of the French AI model: including respect for privacy, protection of personal data, transparency, accountability of actors and contribution to collective wellbeing" (Lemaire \& Mandon, 2017).

\section{Takeaway}

With the UK also trying to assert itself as the AI leader of Europe, France is not the only contestant. Before analyzing these two countries in a global context it is important to note that while the German government pledge to provide around EUR 3 billion for the implementing their AI strategy by 2025, it only allocated EUR 40-50 million to AI (Stix, 2020). Thus, Germany's relatively weaker AI initiative due to its limited resources could create an opportunity for France, rather than a threat; encouraging partnerships and research collaborations that would be mutually beneficial. In addition, even though AI is still in its infancy stage, France - like its European neighbors - have already fallen behind the US and China in numerous categories (later explored). Due to EU's 'umbrella approach' investments done by individual countries like France and Germany remain insignificant compared to its rivals. Even if France doubled its AI budget from EUR 1.5 billion to EUR 3 billion it is still no match for the colossal USD 68 billion investment by the US and USD 70 billion by China. Unlike the ecosystem developed in the US with a bottom-up approach where its tech giants shape the ecosystem through their own interests and company values and China's top-down approach where the government shapes the ecosystem through a single framework, countries like France and Germany are trying to create conditions encouraging ethical and sustainable ecosystem through 'multistakeholder collaboration' argues a report by Access Partnership (Williams, 2018). France's position as a potential AI leader could be strengthened by its soft-power agenda, reducing all the concerns and fears about AI integration.

Whilst the US needs to secure its position it remains AI leader. The US has traditionally led the world in developing and applying AI technologies with the development of its tech giants dominating the digital world. However, its position is increasingly threated due to its weak government initiatives as other governments are aggressively developing new initiatives, all aiming at being world leader in AI. The US industry is led by its tech giants, and the US is seen as a 'gap filler' however this approach may not be sufficient in the long run to outcompete its biggest competitors like China. Considering that AI technology is still in its nascent stage, the USA has the best-established ecosystem, thus able to attract the most top AI talent and develop the greatest number of startups and investments, however other nations like France, Germany and China are rapidly developing their own ecosystems.

The US, China, and EU have all expressed their desires to be leaders in this shift to the fourth industrial revolution powered by AI. After understanding these countries' goals in AI, this paper now examines their implementation. 


\section{Hardware}

\section{What do I mean by hardware in AI?}

Advancement in AI hardware (also referred to as AI chips or AI semiconductors) is imperative to reach the title of leading country in AI. As major corporations and governments are looking to develop AI technology into their systems, semiconductors manufacturers have started to design hardware specifically tailored to support and develop AI. When defining AI hardware there are four main chips involved that can be used in training and developing AI technology, which essentially can then be divided into two categories. (1) Chips originally designed for other computing purposes but that can also be adapted for developing AI technology (e.g. CPU and GPU) and (2) chips that are specifically designed to accelerate AI especially in the fields of artificial neural networks, machine vision and machine learning (e.g. ASIC and FPGA) (AnySilicon, 2019). Both FPGAs and ASICs consume much less energy and allow for greater flexibility in their design, leading to greater speed and lower costs.

Given the broad usage of chips, the best way to analyze a countries AI development in the context of AI hardware is through comparing: (1) the global market share of semiconductor production, (2) the highest performing supercomputers, (3) the development of customizable chips and (4) AI chips investment.

Table 1. Top 15 Semiconductor Sales Leaders (IC Insights)

\begin{tabular}{|l|l|l|}
\hline 2020 Rank & Company & Headquarters \\
\hline 1 & Intel & U.S. \\
\hline 2 & Samsung & South Korea \\
\hline 3 & TSMC & Taiwan \\
\hline 4 & SK Hynix & South Korea \\
\hline 5 & Micron & U.S. \\
\hline 6 & Qualcomm & U.S. \\
\hline 7 & $\begin{array}{l}\text { Broadcom } \\
\text { Inc }\end{array}$ & U.S. \\
\hline 8 & Nvidia & U.S. \\
\hline 9 & TI & U.S. \\
\hline 10 & Infineon & Germany \\
\hline 11 & MediaTek & Taiwan \\
\hline 12 & Kioxia & Japan \\
\hline 13 & Apple & U.S. \\
\hline 14 & ST & Switzerland \\
\hline 15 & AMD & U.S. \\
\hline
\end{tabular}

\section{(1) The Global Market Share of Semiconductor Production}

Many experts believe that chips specifically designed for AI will eventually outperform the multipurpose chips like GPUs. Thus, providing a competitive advantage for the US tech giants like Google, Alphabet, and Apple who are already manufacturing their own AI chips. In terms of general chip-making the U.S. semiconductor industry is the leading manufacturer in the world capturing 47\% of global semiconductor revenue in 2019, generating USD 41 billion, making it the fifth largest export for the US (International Trade Administration). Whilst the US companies have nearly $50 \%$ of the global market share, over $80 \%$ of their sales don't take place in the country. According to Research 
and Markets the "global AI Chip Market was valued at USD 9.29 billion in 2019 and is estimated to garner USD 253.30 billion by 2030”. Developing AI chips is essential for China's and EU's ambition to release independence from American chip-making producers. It is currently reliant on imported chips, due to their "high initial costs and long creation cycle, processor, and chip development [which] may be the most difficult component of China's AI plan" (Wübbeke et al., 2016). According to research firm IC Insights, of the USD 143 billion in chips sold in China in 2020, only USD 22.7 billion worth were produced in China, and only USD 8.3 billion of that was produced by Chinese-headquartered companies (36.5\%), accounting for only 5.9\% of the total market. As per its forecasts, if Chinabased internal circuit manufacturing rises to USD 43.2 billion in 2025 it would still only represent $7.5 \%$ of the total market forecast in 2025 of USD 557.9 billion. Even with significant increases in Chinese-based production of chips, it would still likely represent only $10 \%$ of the global internal circuit market, far from its goal to being world leader in AI development (IC Insights, 2021).

\section{(2) Highest performing supercomputers}

One of the best ways to analyze a countries strength in producing chips is looking at supercomputers, because they are extremely fast, high performance systems that require powerful chips to process the mass amounts of data and massive calculations (Intel). The best benchmark to rank performance of supercomputers is perhaps best done by the TOP500 project which ranks and details the most powerful computer systems in the world. The performance of supercomputers is expressed using floating-point operations per second, also referred to as FLOPS (University Information Technology Services, 2020). China is the leader in this ranking with 219 supercomputers, more than the US with 116 and combined EU with 92. The US position in the development of the world's fastest supercomputers not only shows China's commitment to leading the race for the next forth industrial revolution but also demonstrates China's AI capabilities, as chips remain the backbone for creating an AI ecosystem.

Despite China's growth in supercomputers, Intel continues to dominate the TOP500 ranking where the US companies chip appears $95.6 \%$ of all systems, clearly showing Chinese and European reliance on American chipmakers (TOP500, 2019). Whilst USA remains essential to the production of chipmaking, it is losing global leadership in supercomputer. In 2010, 282 of the TOP500 performing supercomputers in the world were American, now there is only 116. There are also now nine Europe-based supercomputers in the top 25, and the fastest one is Germany-based 'JUWELS'. This shows, that whilst the US is still the leading manufacturer of semiconductor hardware chips, it is slowly losing its position as the most technologically advanced nation in AI technologies.

\section{(3) The number of firms developing customizable chips}

There are two categories of AI chips as previously mentioned, while the first category of 'traditional' chips is currently dominated by US companies; experts are hopeful that the category of 'new' chips will take over the chip market, thus leaving China and other countries in a competitive position.

In the first category of AI hardware producers of GPUs and CPUs are all mainly produced by US companies Nvidia, AMD and Intel. Amongst the top 10 American companies 4 specialize in GPU chip making; in contrast to the top 10 Chinese companies where non are specialized in either (Ding, 2018). According to the Foreign Policy journal, "the only serious Chinese rival to these advanced U.S. chips is the HiSilicon Kirin 9000, designed by Huawei's own in-house 'fabless' chip-design subsidiary" (Babones, 2020). However, amidst sanctions due to US-China trade war the business has greatly suffered as a large sum of its parts were acquired from American manufacturers.

To comprehend why firms are shifting to a GPU system incorporating CPU we must look back to Nvidia's first GPU chip GeForce 256 in 1999; originally designed to increase the processing power of complex computer games. As this technology evolved, in 2010 during the Google Cat photo challenge Nvidia, with 48 GPUs, achieved the same performance as 16,000CPUs - creating a new movement for GPUs (NVIDIA, 2021).

As per the Centre for International Governance Innovation, Intel was the biggest vendor in GPU market with 69\% in Q4 2020, followed by AMD (17\%) and Nvidia (15\%). However, GPUs are not the only hardware platform that can train and execute neural networks. The main argument behind manufacturing hardware in the second category 
- FPGAs and ASICs chips specifically designed for AI - is for its customizability and low power costs. Chinese startups like DeePhi's deep learning processors are entirely dependent on the western chip companies such as, Xilinx's or Intel's FPGA network. As academics like Loskai and Toner argue "the technical dependence on western chip company is not an anomaly - it's industry norm". Companies like Horizon Robotics, world's highest valued AI chip unicorn (Zhang, 2019), rely on Intel's FPGA network for its main processor.

Whilst Chinese companies are currently reliant on Intel's, Nvidia's and AMDs for GPUs and Xilinx's and Altera for FPGA's, there remains one key chip model that hasn't been explored, ASIC. As computer scientist Kai-Fu Lee argues in 'AI Superpowers: China, Silicon Valley, and the New World Order' the AI industry has already experienced the basic innovation in terms of deep learning; now it is how companies can adapt and apply it to specific cases (Lee, 2018). Many specialized AI chips like ASICs, FPGAs and various other neural network processing units have efficiency, cost, and market potential advantages over the GPU; thus, offering a relative 'white space' in which China and Europe can compete (Ma, 2019). Research is increasingly pointing at ASIC to be one of the dominating AI chips; McKinsey projects that GPUs presence in AI training will shift from 97\% (in 2017) to 40\% (in 2025) with ASICs chips drastically rising to 50\% by 2025 (Batra et al., 2019). Given the customizability and other advantages of ASIC chips many scholars like Dantong Ma believe that they are looking promising for China's aim to be a global competitor in this paradigm shift to the fourth industrial revolution. China is leading AI specific chip making companies heavily focused on ASICs chips; six of the top ten companies specialized in production ASICs as of 2018 are Chinese (Gullett \& Bleykhman, 2020). Thierry Breton, the European Industry Commissioner, described the EU market as "too naïve, too open" and has unveiled a strategy in March 2021 with ambitious aim to double production in chips manufacturing to $20 \%$ by 2030 . As well as officials has also aimed to beat industry leaders in the race from 5 nanometers down to 2-nanometers transistors, making the chip more efficient and powerful (Bloomberg, 2021).

The USA is still dominating in the manufacturing of non-specific AI chips; however, Europe and China have developed ambitious goals to decrease reliance on US chips. The production of specific-AI chips still does not have a defined leader giving China an opportunity to decrease dependence on US chips and provide more cost-efficient, flexible chips. Europe has also pledged to decrease reliance on chip-production by doubling its production. As these regions evolve, the US is slowly losing its position as world leader in chip-making but will still likely maintain its strong position for a while.

\section{(4) Investment in AI chips}

Another way of measuring the development of a countries AI chips is by looking at the investments. Global VC investment in semiconductor companies in the first 3 months of 2021 have set a quarterly record for deal value at USD 2.64 billion, with $70 \%$ of the funding going towards Chinese companies according to Pitchbook data. Some experts argue that China is better positions to compete in AI chip market than its biggest rival. The USA is currently dominating the manufacturing of non-AI specific chips due to its lead in the 3IR. However, with most VC investments directed at Chinese startups like Enflame Technology, developing deep learning chips for AI training. It has a total funding amount of approximately USD 500 million including Chinese tech giant, Tencent (Crunchbase, 2021). Similarly, Horizon Robotics, the only one to achieve mass production of AI chips for vehicles in China, have announced plans to raise over USD 700 million to its new series C chip, USD 100 million more than its investment in its series B funding in 2018 capped at USD 600 million (Zhang, 2019). In addition, China's tech giants including Baidu, Tencent, Alibaba, and Huawei, have gained interest in developing AI chips - with Huawei showing promising results as they compete with Apple developing 5nm chips, which refers to the size of the transistors in a processor. Smaller transistors are critical as they are more efficient in terms of power than larger ones. US firms are also developing specialized AI chips like Google's Tensor Processing Unit (TPU) or Apple's new M1 chip. Similarly, the EU aspires to reduce its reliance on overseas production of chips, specifically France and Germany. US tech giant Intel is willing to help the EU achieve its 'dream of semiconductor sovereignty' but requires a commitment of at least USD 10 billion (Hetzner, 2021). Apple will also invest over 1 billion euros in Germany and plans European Silicon Design Center in Munich, focused on $5 \mathrm{G}$ and future wireless technology (Apple, 2021). In terms of investments the in chip making 
companies, Chinese firms have clearly been receiving the most, however the question is whether the Chinese tech giants like Baidu, Alibaba, and Huawei with the support of Chinese government able to outcompete USA's giants. Due to Europe's fragmented approach, they are unable to compete in terms of investments however US firms have increasingly shown an interest in helping Europe develop its own hardware, specifically in France and Germany where US tech giants have installed headquarters.

\section{Takeaway}

The USA is currently dominating the manufacturing of semiconductors and components; it is home to the most powerful computers, with Nvidia, Intel and AMD leading the manufacturing and training of AI hardware. Whilst Chinese companies are currently reliant on Nvidia's GPU model and Xilinx's FPGA for AI development, there remains one key chip model that hasn't been explored, ASICs. Some argue that China is in a better position to compete in AI chip market than its rival as the growing interest its Chinese giants have shown in AI chips and the increasing number of investments in AI-specific chip making startups. Also, France and Germany still remain extremely weak in terms of manufacturing of AI hardware however some US and Chinese companies have shown interest in developing AI technology in EU, specifically France, Germany, and China.

\section{AI R\&D}

Google Scholar, the largest database for academic papers of its kind, released a ranking of the most highly cited papers announcing that "AI research dominated again" (Crew, 2020). Governments and firms in China, United States and the European Union have all launched initiatives to promote AI R\&D, attempting to attract AI talent, and thereby increasing their competitiveness on an international stage. In this section AI R\&D is defined as any research or innovative initiatives conducted by companies or governments to improve and grow existing knowledge in the domain of AI (Kenton \& James, 2021). This section analyses the success of each countries AI R\&D through (1) AI research output and influence, (2) AI Patents and (3) AI Talent. Compiling indicators to compare AI development amongst nations is essential to understanding the influence they each have on AI development, and thus potential in terms of innovation and AI capabilities

\section{(1) AI Research}

As per a report released by Tsinghua University, "it was found that $58.64 \%$ of AI papers were proceeding papers, showing that proceeding papers are important sources of AI research output". This section defines AI paper output as any related AI proceeding papers, articles, reviews, book chapters or any other literary works published between 1997 and 2017. The last 20 years, many countries have attempted to develop their own paths towards AI research; China is the current leader in terms of total AI paper output with 369,588 publications, ahead of the USA $(327,034)$ and the EU (combined score of 328,630). Indeed, the combined AI paper output of the leading countries in the European Union from: UK (96,536), Germany $(85,587)$, France $(72,261)$, Spain $(58,582)$, Poland $(25,592)$, and Netherlands $(25,138)$ is greater than the United States. As well as, amongst the top 20 research institutions in AI specific output the two major institutes that are leading research is the Chinese Academy of Sciences Systems and the French National Center for Scientific Research. Of the 20 contestants, 13 are based in the EU; with France, Germany and the US being the three most featured each with three titles (Tsinghua University, 2018). Whilst the EU may have a lead in the number of research institutions in terms of AI output; of the top 20 companies leading AI research in 2019, 10 of them were American, including the first 4 with Google, Microsoft, Facebook, and Amazon (Chuvpilo, 2020). In terms, of AI research China and the USA are the two leading countries both showing dedication in research, however when considering the EU as a whole it also surpasses the US. Leading European countries like the UK, France, and Germany are playing a significant role in shaping AI research in the European region and show great AI potential. 
However, it is not the amount of AI specific output that is produced, but their impact. As Jeffrey Ding wrote, “just pumping out raw numbers of papers that don't have a lasting impact isn't really useful”. Formulating a logical relationship between the published articles and published references will provide accurate data assessing a paper's influence. The more frequently cited the paper the more influence it has (Tsinghua University, 2018). To ensure a reliable comparison method this report adopts the H-Index which is widely recognized in the academic community as "an estimate of the importance, significance, and broad impact of a scientist's cumulative research contributions" (Hirsch, 2005). As per a report published by McKinsey Global Institute on AI, although China produces a large number of widely cited AI-related papers, US and UK research remains much more influential (Barton et al., 2017). While the United States is currently leader in publication influence, given the nature of AI race, it is essential to promote international cooperation with 'likeminded democracies' (Kerry, 2021). Collaboration in AI R\&D has become essential to "liberate silos, protect privacy and security, and maintain efficiency" notes Intel, leading company in AI (Intel, 2021). In 2018 the Tsinghua University calculated that international collaborative research papers on AI represent $23.42 \%$ of all AI papers but as high as $42.64 \%$ of all top papers on AI and even more than $50 \%$ of all top papers on AI of the top 10 countries with the greatest output of top papers on AI. According to a report released by Stanford, US authors are cited 40\% more than the world average regarding AI papers (Shoham et al., 2019). It is essential for the European Union to follow a similar approach to France, which holds the highest percentile in industry collaborative papers, and is heavily investing in AI research. China produces the most AI research however in terms of quality it has far less influence than the US and is close to the UK.

\section{(2) AI Patent}

Due to different definitions of AI technology, it is complicated to directly compare the difference in investment in aggregate investment (both regarding private and public sector). Thus, an alternative measure of comparing the success of AI R\&D is through investments in AI patents. A 'patent application' is defined as an application submitted in one jurisdiction and published in that same jurisdiction; a patent can be re-published during processing (eg. later research, grants, corrections) however is only counted the first time it is published. A 'patent family' is defined as "a group of patent applications made and published in different jurisdictions". Each patent in a patent family is related to a single invention (UK Intellectual Property Office, 2019). As per data collected by the Intellectual Property Office in, the US remains the leading country in overall published AI patent application with nearly 50000, despite China's exponential increase with just above 40000 and Germany placing $7^{\text {th }}$ and France placing $17^{\text {th }}$ both of which are under 5000 publications. As well as the importance in the IP5s is also worth noting, with WIPO and EPO ranked $3^{\text {rd }}$ and $5^{\text {th }}$ above any European countries.

However, it is essential to analyze the countries AI applications published in each of the IP5s per year to understand which countries are driving the recent 'AI patents boom'. The IP5s are defined as the largest intellectual property offices in the world which were designed to improve efficiency in the review process of patents worldwide, these include: the European Patent Office (EPO), the Japan Patent Office (JPO), the Korean Intellectual Property Office (KIPO), the National Intellectual Property Administration of the People's Republic of China (CNIPA) and the United States Patent and Trademark Office (UPSTO). Analyzing these IP5 Offices is essential as together they are responsible for $80 \%$ of the world's patent applications (IP5 Office, n.d.). According to a report published by WIPO, patents relating to AI skyrocketed in the last 5 years representing 50\% of all patents published; as well as AI patent families grew on average by 28\% annually between 2012 and 2017 (World Intellectual Property Organization, 2019). As per data from the Intellectual Property Office, China is largely responsible for the growth in published patent applications in recent years. Whilst the US remains the leading country in total published patents since 1998, China is rapidly closing the gap whilst European countries are falling behind.

Another way to understand the recent 'AI patent boom' is looking at the top applicants worldwide in terms of AI patent families. Companies particularly in Japan, USA and China are dominating patent activity. According to a report published by WIPO, companies represent 26 of the top 30 AI patent applicants, with only 4 universities and public research institutions. Across different AI-related patents, Microsoft, and IBM rank first and second in most AI 
techniques with a total 8290 and 5930 inventions respectively. As well as of the top 20 companies, 12 are Japanese, 2 from the republic of Korea (Samsung and LG Corporation) and 2 from Germany (Bosch and Siemens). According to calculations done by Diakun, the top 3 companies after IBM and Microsoft are Toshiba (5223), Samsung (5102) and NEC (4406). As argued by the report, there are companies who strive in specific areas of AI, for example, Baidu in deep learning, or Toyota and Bosch in transportation. As well as, of the 4 university and research organization 3 are Chinese, these could be explained by China's bottom-up approach. In contrast to the west, $52 \%$ of the China's top 30 assignees for AI patents are by academia. Out of the top 20 universities and public research institutions in the domain of AI technologies, 17 are Chinese with the remaining 2 being in the Republic of Korea. The two largest patent portfolios are the Chinese Academy of Sciences (CAS) which ranks $17^{\text {th }}$ and the Korean Electronics and Telecommunications Research Institute (ETRI) which ranks 20 (World Intellectual Property Organization, 2019). The race for AI innovation is clearly multisectoral, fragmented across multiple disciplines. The leading overall companies remain overall leaders in AI innovations however are increasingly facing competitions by Asian based companies.

\section{(3) AI talent}

The difference in AI research may also be due to AI talent. Researchers are essential for progress in AI development; as Nick Zhang, president of the Wuzhen Institute, an AI think tank in Wuzhen said, "it's a talent war - whoever makes the best offer wins". AI talent is defined as individuals who possess a technical and creative expertise that encompasses statistical modeling and big data computational skills*, conducting active AI research and formulating innovative outcomes (LinkedIn, 2019). According to LinkedIn the aggregate demand for AI talent grew by $74 \%$ annually between 2016-2019 (LinkedIn, 2020). This section analyses the AI talent of each of the three countries through (1) the number of AI researchers, (2) the number of top AI researchers, (3) location of AI researchers' graduate degrees. The AI talent pool is scarce, densely distributed amongst the United States, China, India, and some countries in Europe. The United States has an estimate of 28,536 people ahead of China $(18,232)$ and India (17384). However, the combined score of Europe is 43,064, making it a major player in AI talent. The combined number of AI talent from Germany (9,441), the United Kingdom (7,998), France (6,395), Spain (4,942), and Italy (4,740) was 33,516 - greater than USA's AI talent (Tsinghua University, 2018). Whilst the data for the other 23 EU nations were unavailable the EU has enough AI talent, thus AI potential, to outcompete its biggest rival, USA. While China accounts for $8.9 \%$ of total AI pool, it only holds $5.4 \%$ of the top AI talent of all AI talent in the country, as shown in table 2; behind the USA (18.1\%), the UK (14.7\%), Germany (11.9\%), France (16.5\%) and Italy (20.8\%). AI talent is clearly mal distributed across Member States, with just three countries accounting for almost half of the total EUs AI talent. In order to transform the EU as a global leader in AI technology, they should equalize the distribution of AI talent across EU and create a single approach to strengthen its AI ecosystem. China's lack of AI talent could be due to its relatively new interest in AI, with only $25 \%$ of Chinese AI talent having more than 10 years of experience compared to the US with nearly $50 \%$ (Qingqing, 2017).

Table 2. The Global Distribution of top AI Talent, top AI talent as a percentage of all AI talent in each country (Tsinghua University, 2018)

\begin{tabular}{|l|l|l|l|}
\hline Country & Number of top AI Talent & $\begin{array}{l}\text { Number of Total AI Tal- } \\
\text { ent }\end{array}$ & $\begin{array}{l}\text { Top AI talents as percent- } \\
\text { age of all AI talent in } \\
\text { each country }(\%)\end{array}$ \\
\hline USA & 5158 & 28536 & 18.1 \\
\hline UK & 1177 & 7998 & 14.7 \\
\hline Germany & 1119 & 9441 & 11.9 \\
\hline France & 1056 & 6395 & 16.5 \\
\hline Italy & 987 & 4740 & 20.8 \\
\hline China & 977 & 18232 & 5.4 \\
\hline Spain & 772 & 4740 & 15.6 \\
\hline
\end{tabular}




\begin{tabular}{|l|l|l|l|}
\hline Japan & 651 & 3117 & 20.9 \\
\hline Canada & 606 & 4228 & 14.3 \\
\hline Australia & 515 & 3186 & 16.2 \\
\hline
\end{tabular}

The distribution of AI talents by affiliated entity worldwide by the end of 2017 showed that $73.3 \%$ of all AI talent came from universities and $15 \%$ from research institutions. Thus, analyzing the development of AI talent through these two lenses is essential to understanding a countries total potential (Statista, 2017). As shown in table below the leading contributors in academics with the highest concentration of AI talents are dominated by China, with 11 of the 20 universities listed. However, when compared to the top international AI talent Tsinghua University, the only Chinese university, is classed $15^{\text {th }}$ of the 20 ranked with half of them being American (Tsinghua University, 2018).

Table 3. International AI talent by affiliated university (Tsinghua University, 2018)

\begin{tabular}{|l|l|l|}
\hline University & Number of AI Talent & Country \\
\hline Tsinghua University & 822 & China \\
\hline Shanghai Jiao Tong University & 590 & China \\
\hline Vellore Institute of Technology & 526 & India \\
\hline Beihang University & 525 & China \\
\hline Carnegie Mellon University & 523 & USA \\
\hline Zhejiang University & 506 & China \\
\hline Huazhong University of Science and Technology & 465 & China \\
\hline Peking University & 463 & China \\
\hline Wuhan University & 446 & China \\
\hline Beijing University of Posts and Telecommunications & 443 & China \\
\hline
\end{tabular}

Table 4. Top international AI talent by affiliated university (Tsinghua University, 2018)

\begin{tabular}{|l|l|l|}
\hline University & Number of AI Talent & Country \\
\hline Stanford University & 79 & USA \\
\hline Massachusetts Institute of Technology & 72 & USA \\
\hline University College London & 67 & UK \\
\hline University of Washington & 60 & USA \\
\hline University of São Paulo & 60 & Brazil \\
\hline University of Michigan & 55 & USA \\
\hline University of Toronto & 53 & Canada \\
\hline University of California, San Diego & 51 & USA \\
\hline University of California, Berkeley & 51 & USA \\
\hline University of California, Los Angeles & 49 & USA \\
\hline
\end{tabular}

As seen with the past industrial revolutions, nations that lag in adoption of AI technology and underinvest in AI R\&D will experience significant loss in global market share the countries geopolitical and economic influence as well. With China's re-emergence as a global superpower "it will be the economic question of who Googles will be, Amazons and Apples in 2020" says Andrew Moore, dean of computer science at Carnegie Mellon University. Whilst the US remains leader in AI R\&D, China's commitment to becoming leader in this industry by 2030 is presenting a growing threat to its hierarchy. The EU's umbrella strategy for AI deliberately provides a holistic approach emphasizing regulatory and ethical frameworks, however if the EU wants to maintain global competitiveness, they must strengthen its technological and industrial competitiveness as well as attract a greater amount of AI talent. 


\section{Takeaway}

Although China is one of the most active countries in terms of AI research with the highest number of AI talent, research institutions and papers published, the US and Europe are far more influential in terms of their output. This section shows that the US and leading European countries like UK, France and Germany have great amounts of AI capabilities due to the high quality of its output. This pattern persists not only in AI Research but also in AI Development, where China once again supersedes the US and Europe in terms of quantity but stumbles when quality is examined.

\section{AI Ecosystem}

In addition to AI Research, another important area of exploration is the AI ecosystem. For nations to fully benefit from the development of AI they must first develop a healthy ecosystem that will attract AI talent, thereby developing research and innovation. It is important to note that unlike other ecosystems, the AI Ecosystem cannot be associated to a single industry, "but rather it is composed of multiple, interconnected enabling technology sub-industries (henceforth referred to as segments) - such as machine learning, robotics, computer vision, or natural language processing. Each of these technology segments will have their own trajectories, but they must be considered in relation to the other segments in order to get a true systemic understanding of AI ecosystem evolution" defines Rahul C. Basole, Associate Professor in the School of Interactive Computing and a Director of the Institute for People \& Technology (Basole, 2021). This section analyses the development of AI Ecosystem of China, US, and Europe through (1) funding of AI start-ups and (2) the number of AI startups.

\section{(1) Funding of AI start-ups}

New analysis by the OECD, using data from Crunchbase, found that AI start-ups have so far attracted around 12\% of all worldwide private equity investments in the first half of 2018, a significant increase from just $3 \%$ in 2011 (Breschi et al., 2018). China has seen an upsurge in spending from 2016 in total investments and now appears to be the second leader in terms of AI equity investments received; this growth reflects China's efforts and government initiatives like the Made in China 2025 announcing its ambition to dominate key technologies identified like AI, 5G and semiconductors to name a few (Wübbeke et al., 2016). The EU accounted for 8\% of global AI equity investment in 2017, representing a significant increase for region compared to 2013 (with only 1\%). However, according to data recorded in Crunchbase, the investment in AI start-ups is extremely varied throughout member states. With the UK dominated with $55 \%$ of total amount; followed by the Germany (14\%) and France (13\%), implying that the rest of the 25 member states account for less than $20 \%$ of all investments in AI received in the EU. As expected, US attracted a significant proportion of all investment deals, China transitioned from having no deals in 2011 to 60 in 2017, showing China's rapid growth as well as surpassing the EU in higher average deals (Breschi et al., 2018). Digital giants like Google and Baidu are also heavily investing in the acquisition of AI startups, aiming to attract and harness the most AI talent as possible. According to CB Insights from the major mergers and takeovers (M\&A) deals in Jan 2011 - Feb 2017, there were nearly $60 \%$ conducted by American tech giants; with Google dominating at 11 deals ahead of, Apple (5), Intel (5) and Microsoft (4). As well as of the 10 major M\&A deals including VC Investments, 9 of the 10 were by the Chinese tech giants. With Tencent leading with 5 ahead of Baidu (2), Alibaba (1) and JD (1). As well as from 2017 2018, U.S. AI firms received the most investments (1,270 deals) ahead of the European Union (660) and China (390). Per one million workers, the United States (8 deals) led the European Union (3) and China (0.5) (Castro, 2019). The three main patterns that should be remembered is that: (1) Chinese start-ups have had unprecedented growth in the last from 2013 to 2017, (2) the USA has the largest M\&A deals including VC Investments, with a steady growth and (3) such difference in investment in the EU could fuel a gap between the UK, France and Germany and other member states. 


\section{(2) Number of startups}

As the pace for AI intensifies and businesses are trying to join the multisectoral race to integrate into their products, the pool for AI talents is becoming even more scarce. Roland Berger, a global consultancy, and Asgard, a Berlinbased investment firm, has categorized AI startups and digital platforms as the "players creating algorithms and developing use cases, they are the brains behind innovation". In their report on AI, they defined an AI company as "one that produces a primary product or service utilizing machine learning, deep learning, image recognition, natural language processing or other frontier AI technology". According to the study, the US dominates the race for startups, accounting for 1393 startups - representing approximately $40 \%$ of the global distribution. China is ranked second with 383 startups (11\% of the total worldwide) and Israel in third place with 362 startups (10\%). However, if we consider Europe as whole it equates to 769 AI startups or $22 \%$ of global distribution with the UK (245), France (109) and Germany (106). The leading regional hub is San Francisco with 596 startups, followed by London (211), Tel Aviv (189), New York (180) and Beijing (150) (Roland Berger, 2018). While the UK will remain the powerhouse of European AI for many years, Brexit has allowed other European countries like France and Germany to extend their influence. This is because a key part of London's tech ecosystem originates from overseas talent attracting roughly "one in five London tech workers [being] European; one in three is from overseas' making them a big portion of the ecosystem" says an article by Soldo. As well as data from CB Insights regarding the top 100 startups, the US and EU outcompete China.

In keeping with the AI research section, this examination of the AI ecosystems finds that China leads in terms of quantity but not necessarily quality. In both the start-up and funding space, China does outcompete its rivals in terms of quantity; however, the US and Europe do have higher quality of output especially regarding the strength of their ecosystem. Whilst China does have an advantage over Europe with its tech giants like Baidu and Alibaba, Europe, specifically France and Germany, is prioritizing sustainable growth over rapid growth.

\section{Conclusion and Implications}

The development of AI will have an impact beyond the realms of technology and efficiency, it will have both immediate and long-term impacts on society and completely change the balance of power on an international stage. Given AI's 'omni-use' the approaches to defining this concept has become ever so different; fundamentally, it refers to a program whose objective is to understand and reproduce human cognition through interpreting vast amounts of data. AI technology is one of the few technologies that can revolutionize every sector, however, is reliant on large amounts of data, research, and collaboration in order to develop. Hence, understanding the ambition and initiatives of the three major players, the US, China, and the EU, specifically France and Germany, is essential to formulating an argument to who is going to lead this fourth industrial revolution, and therefore transform the global power distribution. In the article, I argue that $\mathrm{AI}$ is at the epicenter of the fourth industrial revolution and will, similarly to previous industrial revolutions, completely transform global governance; especially regarding the world order established by the United States after its inherited 'unipolarity' in 1991. The implications of this paper suggest that the international system is moving from unipolarity towards multipolarity with Europe and China at the forefront of this movement.

Whilst the United States needs to secure its position, it remains leader in AI technology due to its undeniable strength in core AI development. Notably its dominance in the manufacturing of AI hardware; as well as its strong AI ecosystem fostering top AI startups and talent. It is also home to tech giants like the Nvidia and Alphabet who secure large amounts of investments and research; hence, providing the perfect platform for innovation in AI technology. China has been experiencing unprecedented growth ranking amongst the leading countries in AI development, and is indeed an increasing threat to USA's leadership in this field. Beijing has become the number one city in AI development and potential, in terms of number of enterprises, talent, research institutions, venture capital, startups and innovations. However, despite its rapid growth it remains weak in several indicators, especially regarding the quality of its development. Although its numbers are next to the United States in multiple criterium like AI papers or AI talent, when only considering top tier output, there is a significant gap between US and European countries, notably France 
and Germany. Thus, China is still far from its goal to be world leader and still remains behind the US overall; however, outcompetes other countries like Germany and France.

In terms of areas for future research, at present, AI still lacks a universal definition, making data collection tricky to analyze. Although this paper draws from multiple definitions of AI and analyzes the influence of AI through different categories, other papers may be interested in examining different categories. The research can also be further expanded to examine other European states and develop a holistic narrative, particularly as the European Union takes on questions of AI regulations. Moreover, given the nature of AI and data availability, this report only considers the commercial usage of AI, completely excluding its military capacity. The framework examined here has direct implications for states' ability to develop and deploy these artificial intelligence assets for military and security purposes. Given the categories examined here, there are also direct implications for ethical and regulatory frameworks, as well as the sustainable growth of AI development. Whilst nations are racing for AI innovations, the next step will be developing global governance of AI, which plays a prominent role in AI development, risk prevention and formulating ethical norms. This paper serves as a grounding point for these questions by adding in Europe to the US-China rivalry and utilizing a concise framework to evaluate each state's artificial intelligence capabilities.

In the long term, the leading countries in AI technology will be those who opt for sustainable growth and coordinated strategy, with a fluid relationship between the private and public sector and not at the detriment of society. In this respect the United States and China are clearly at an advantage with its global digital players, Google, Apple, Facebook, Amazon, and Microsoft (GAFAM) and China's Baidu, Alibaba, Tencent and Xiaomi (BATX). These companies with the support of government initiatives have access to all the necessary components to nurture a strong AI ecosystem with the ability to attract top AI talent, access to state-of-the-arts technology and access large amounts of funding and data. Europe, often forgotten, is also a key player in developing AI technology due to its large potential; however, its fragmented approach may result in AI being a source of differentiation, creating a gap within Europe. The EU combined has the capability to compete and even outcompete the US and China in numerous disciplines however without a strong, unified ecosystem they will not be able achieve the critical mass it requires to maintain its competitiveness on an international stage. Thus, Europe must rapidly develop an ambitious, unified AI policy vision centered around developing, like its rivals, a strong ecosystem - keeping startups at its heart.

\section{Acknowledgements}

I would like to acknowledge with thanks the continuous support of Lumiere Education notably Dhruva Bhat and Stephen Turban and the anonymous reviewers for whom this article would not have been possible. I am also grateful for my advisor, Emma Campbell-Mohn for her mentorship, comments, and guidance throughout this project.

\section{References}

AnySilicon. (2019, August 19). Introduction to Artificial Intelligence in ASICs. AnySilicon. https://anysilicon.com/introduction-to-artificial-intelligence-in-asics/

Apeldoorn, B. V., \& Graaff, N. de. (2015). American Grand Strategy and Corporate Elite Networks: The Open Door since the End of the Cold War. Routledge.

Apple. (2021). Apple to invest over 1 billion euros in Germany with new Munich campus. Apple Newsroom (United Kingdom). https://www.apple.com/uk/newsroom/2021/03/apple-to-invest-over-1-billion-euros-in-germany-withnew-munich-campus/ 
Babones, S. (2020). China's Drive to Make Semiconductor Chips Is Failing. Foreign Policy. https://foreignpolicy.com/2020/12/14/china-technology-sanctions-huawei-chips-semiconductors/

Barton, D., Woetzel, J., Seong, J., \& Tian, Q. (2017). DISCUSSION PAPER PRESENTED AT THE 2017 CHINA DEVELOPMENT FORUM. 20.

Basole, R. (2021). Visualizing the Evolution of the AI Ecosystem. https://doi.org/10.24251/HICSS.2021.747

Batra, G., Jacobson, Z., Madhav, S., (Europe Looks to Secure Chip, A., \& Santhanam, N. (2019). AI hardware: Value creation for semiconductor companies | McKinsey.

https://www.mckinsey.com/industries/semiconductors/our-insights/artificial-intelligence-hardware-newopportunities-for-semiconductor-companies\#

Bloomberg. (2021, May 5). Europe looks to secure chip supply after “naive” past approach. Automotive News Europe. https://europe.autonews.com/suppliers/europe-looks-secure-chip-supply-after-naive-past-approach

Breschi, S., Lassébie, J., \& Menon, C. (2018). A portrait of innovative start-ups across countries (OECD Science, Technology and Industry Working Papers No. 2018/02; OECD Science, Technology and Industry Working Papers, Vol. 2018/02). https://doi.org/10.1787/f9ff02f4-en

Castro, D. (2019, August 19). Who Is Winning the AI Race: China, the EU or the United States? Center for Data Innovation. https:/datainnovation.org/2019/08/who-is-winning-the-ai-race-china-the-eu-or-the-united-states/

Chuvpilo, G. (2020, December 20). AI Research Rankings 2019: Insights from NeurIPS and ICML, Leading AI Conferences. Medium. https://chuvpilo.medium.com/ai-research-rankings-2019-insights-from-neurips-and-icmlleading-ai-conferences-ee6953152c1a

Crew, B. (2020). Google Scholar reveals its most influential papers for 2020. https://www.natureindex.com/newsblog/google-scholar-reveals-most-influential-papers-research-citations-twenty-twenty

Crunchbase. (2021). Enflame-Crunchbase Company Profile \& Funding. Crunchbase. https://www.crunchbase.com/organization/suiyuan-technology

DARPA. (2019, September). AI Next Campaign. https://www.darpa.mil/work-with-us/ai-next-campaign Ding, J. (2018, March). Deciphering China's AI Dream. https://www.dx2025.com/wpcontent/uploads/2019/11/deciphering-chinas-ai-dream.pdf

European Commission. (2019). HIGH-LEVEL EXPERT GROUP ON ARTIFICIAL INTELLIGENCE. Shaping Europe's Digital Future. https://digital-strategy.ec.europa.eu/en/policies/expert-group-ai

European Commission. (2020). COMMUNICATION DE LA COMMISSION AU PARLEMENT EUROPÉEN, AU CONSEIL, AU COMITÉ ÉCONOMIQUE ET SOCIAL EUROPÉEN ET AU COMITÉ DES RÉGIONS.

European Commission. (2021). France AI Strategy Report | Knowledge for policy. https://knowledge4policy.ec.europa.eu/ai-watch/france-ai-strategy-report_en

Federal Ministry of Education and Research. (n.d.). Industrie 4.0. Bundesministerium Für Bildung Und Forschung BMBF. Retrieved May 11, 2021, from https://www.bmbf.de/de/zukunftsprojekt-industrie-4-0-848.html 
Federal Ministry of Education and Research, Federal Ministry for Economic Affairs and Energy, \& Federal Ministry of Labour and Social Affairs. (2018). Germany AI Strategy Report | Knowledge for policy. https://www.ki-strategiedeutschland.de/home.html?file=files/downloads/Nationale_KI-Strategie_engl.pdf

Gelles, R., Hwang, T., \& Rodriguez, S. (2021). Mapping Research Agendas in U.S. Corporate AI Laboratories. Center for Security and Emerging Technology. https://doi.org/10.51593/20200037

Graham Webster, Rogier Creemers, Paul Triolo, \& Elsa Kania. (2017). Full Translation: China's "New Generation Artificial Intelligence Development Plan” (2017). New America. http://newamerica.org/cybersecurityinitiative/digichina/blog/full-translation-chinas-new-generation-artificial-intelligence-development-plan-2017/

Gullett, M., \& Bleykhman, S. (2020). China's Bid To Lead Artificial Intelligence Chip Development within the Decade (LLNL-TR-815497, 1673195, 1024464; p. LLNL-TR-815497, 1673195, 1024464). https://doi.org/10.2172/1673195

Hetzner, C. (2021). Intel ready to help Europe achieve its long stated goal of chips self-sufficiency-But it won't come cheaply. Fortune. https://fortune.com/2021/05/03/intel-europe-semiconductor-self-sufficiency-eu-germany/

Hirsch, J. E. (2005). An index to quantify an individual's scientific research output. Proceedings of the National Academy of Sciences, 102(46), 16569-16572. https://doi.org/10.1073/pnas.0507655102

Hoppe, M. H., \& Bhagat, R. S. (2007). Leadership in the United States of America: The Leader as Cultural Hero. In Culture and Leadership Across the World. Psychology Press.

Horowitz, M. C., Allen, G. C., Kania, E. B., \& Scharre, P. (2018). Strategic Competition in an Era of Artificial Intelligence. 27.

Huang, Y. (2012). How Did China Take Off? The Journal of Economic Perspectives, 26(4), 147-170.

IC Insights. (2021, January). China Forecast to Fall Far Short of its “Made in China 2025” Goals for ICs. https://www.icinsights.com/news/bulletins/China-Forecast-To-Fall-Far-Short-Of-Its-Made-In-China-2025-GoalsFor-ICs/

Intel. (n.d.). What Is Supercomputing? Intel. Retrieved May 25, 2021, from

https:/www.intel.com/content/www/us/en/government/exascale-supercomputing.html

Intel. (2021). Private AI Collaborative Research Institute Launch. Intel.

https://www.intel.com/content/www/us/en/research/blogs/private-ai-collaborative-research-institute-launch.html

International Trade Administration. (n.d.). Semiconductors. Retrieved May 25, 2021, from

http://www.trade.gov/semiconductors

IP5 Office. (n.d.). About IP5 co-operation. Retrieved May 25, 2021, from https://www.fiveipoffices.org/about Jinping, X. (2017, October). Secure a Decisive Victory in Building a Moderately. http://www.xinhuanet.com/english/download/Xi_Jinping's_report_at_19th_CPC_National_Congress.pdf

Kagermann, Lukas, \& Wahlster. (2013, March). Industry 4.0: With the Internet of Things on the way to the 4th industrial revolution - vdi-nachrichten.com. https:/web.archive.org/web/20130304101009/http://www.vdi- 
nachrichten.com/artikel/Industrie-4-0-Mit-dem-Internet-der-Dinge-auf-dem-Weg-zur-4-industriellenRevolution/52570/1

Kennedy, P. (1988). The Rise and Fall of Great Power. https://www.cia.gov/library/abbottabadcompound/04/04A70DD54F5CB55BED6BE3B351E242EE_The_Rise_and_Fall_of_Great_Power_Paul_Kennedy.p df

Kenton, W., \& James, M. (2021). Why Research and Development (R\&D) Matters. Investopedia. https://www.investopedia.com/terms/r/randd.asp

Kerry, J. P. M. and C. F. (2021, February 17). Strengthening international cooperation on artificial intelligence. Brookings. https://www.brookings.edu/research/strengthening-international-cooperation-on-artificial-intelligence/

Kratsios, M. (2019). The National Artificial Intelligence Research and Development Strategic Plan: 2019 Update. 50 .

Kratsios, M., \& Parker, L. E. (2020). American Artificial Intelligence Initiative: Year One Annual Report. 36.

Krauthammer, C. (1990). The Unipolar Moment. Foreign Affairs, 70, 23.

Lam, T., Li, F., Han, Z., \& Chung, R. (2019). Global artificial intelligence industry whitepaper. https:/www2.deloitte.com/content/dam/Deloitte/cn/Documents/technology-media-telecommunications/deloitte-cntmt-ai-report-en-190927.pdf

Lee, K.-F. (2018). AI Superpowers: China, Silicon Valley, and the New World Order. Houghton Mifflin Harcourt.

Lemaire, A., \& Mandon, T. (2017, January 26). \#FranceIA: The national artificial intelligence strategy is underway. Gouvernement.Fr. https://www.gouvernement.fr/en/franceia-the-national-artificial-intelligence-strategyis-underway

Li, G., \& Ruiyang, Z. (2016, March). The Google DeepMind Challenge Match. Deepmind. /alphago-korea

LinkedIn. (2019, November). AI Talent in the European Labour Market.

https:/economicgraph.linkedin.com/content/dam/me/economicgraph/en-us/reference-cards/research/2019/LinkedInAI-Talent-in-the-European-Labour-Market.pdf

LinkedIn. (2020). 2020 Emerging Jobs Report. https://business.linkedin.com/content/dam/me/business/en-us/talentsolutions/emerging-jobs-report/Emerging_Jobs_Report_U.S._FINAL.pdf

Ma, J. D. (2019, September 10). Chip on the Shoulder: How China Aims to Compete in Semiconductors. MacroPolo. https://macropolo.org/china-chips-semiconductors-artificial-intelligence/

McCarthy, J. (n.d.). WHAT IS ARTIFICIAL INTELLIGENCE? 15.

Messe, H. (2019, April). Background to the Industry 4.0 platform. https://www.plattformi40.de/PI40/Navigation/DE/Plattform/Hintergrund/hintergrund.html 
Meurier, A.-L., Ghafoor, Z., Foehrenbach, C., Hartmann, C., Herzog, J., Madzou, L., \& Narzul, R. (n.d.). Mission assigned by the Prime Minister Édouard Philippe. March 2018, 154.

Mozur, P. (2017, July 20). Beijing Wants A.I. to Be Made in China by 2030. The New York Times. https://www.nytimes.com/2017/07/20/business/china-artificial-intelligence.html

NVIDIA. (2021). GTC 2021: \#1 AI Conference. NVIDIA. https:/www.nvidia.com/en-us/gtc/

Philbeck \& Davis. (2019, January 22). The Fourth Industrial Revolution: Shaping A New Era. JIA SIPA. https://jia.sipa.columbia.edu/fourth-industrial-revolution-shaping-new-era

Qingqing, Y. (2017). The search model faces the ceiling, Baidu's president changes to upgrade its artificial intelligence strategy-21st Century Business Herald. http://epaper.21jingji.com/html/2017-01/18/content_54928.htm

Roberts, H., Cowls, J., Morley, J., Taddeo, M., Wang, V., \& Floridi, L. (2021). The Chinese approach to artificial intelligence: An analysis of policy, ethics, and regulation. AI \& SOCIETY, 36(1), 59-77.

https://doi.org/10.1007/s00146-020-00992-2

Roland Berger. (2018). AI Strategy for European Startups.

Schwab, K. (2017). The Fourth Industrial Revolution. Crown.

Shoham, Y., Brynjolfsson, E., Clark, J., Etchemendy, J., Grosz, B., Lyons, T., Manyika, J., Mishra, S., \& Niebles, J. C. (2019). AI Index 2019 report (p. 291). https://hai.stanford.edu/sites/default/files/ai_index_2019_report.pdf

Statista. (2017). AI talent by affiliated entity worldwide 2017. Statista. https://www.statista.com/statistics/947115/aitalent-by-affiliated-entity-worldwide/

Stix, C. (2020). The European AI Landscape.

https:/ec.europa.eu/jrc/communities/sites/jrccties/files/reportontheeuropeanailandscapeworkshop.pdf

The Federal Republic of Germany. (2020). German Draft Budgetary Plan.

https:/ec.europa.eu/info/sites/default/files/economy-finance/2020_dbp_de_en.pdf

TOP500. (2019). TOP500 Becomes a Petaflop Club for Supercomputers | TOP500.

https://www.top500.org/news/top500-becomes-a-petaflop-club-for-supercomputers/

Trump, D. (2019, February). Maintaining American Leadership in Artificial Intelligence. Federal Register. https://www.federalregister.gov/documents/2019/02/14/2019-02544/maintaining-american-leadership-in-artificialintelligence

Trump, D. (2020). A Budget for a Better America. https://www.govinfo.gov/content/pkg/BUDGET-2020BUD/pdf/BUDGET-2020-BUD.pdf

Tsinghua University. (2018). China AI development report 2018. http://www.sppm.tsinghua.edu.cn/eWebEditor/UploadFile/China_AI_development_report_2018.pdf 
UK Intellectual Property Office. (2019). Artificial intelligence: A worldwide overview of AI patents and patenting by the UK AI sector.

University Information Technology Services. (2020). Understand measures of supercomputer performance and storage system capacity. https://kb.iu.edu/d/apeq

van Heuven, M. (1993). The U.S. Role in Post-Cold War Europe: Significance of European Views of the New U.S. Administration. https://www.rand.org/pubs/monograph_reports/MR404.html

Villani, C. (2018, March). AI for humanity. https://www.aiforhumanity.fr

Williams, K. (2018). France's AI Funding Can't Match China's, But It Doesn't Need To. Access Partnership. https://www.accesspartnership.com/frances-ai-funding-cant-match-chinas-but-it-doesnt-need-to/

Wohlforth, W. C. (1999). The Stability of a Unipolar World. International Security, 24(1), 5-41. https://doi.org/10.1162/016228899560031

World Intellectual Property Organization. (2019). WIPO Technology Trends 2019: Artificial Intelligence.

Wübbeke, J., Meissner, M., Zenglein, M. J., Ives, J., \& Björn Conrad. (2016, December). Made in China 2025—The making of a high-tech superpower and consequences for industrial countries. https://kritischesnetzwerk.de/sites/default/files/merics_-_made_in_china_2025_-_the_making_of_a_hightech_superpower_and_consequences_for_industrial_countries_-_76_seiten_1.pdf

Zeng, J. (2021). China's Artificial Intelligence Innovation: A Top-Down National Command Approach? Global Policy. https://doi.org/10.1111/1758-5899.12914

Zhang, B. (2019, February 27). China's Horizon Robotics Becomes the World's Highest Valued AI Chip Unicorn. Pandaily. https://pandaily.com/chinas-horizon-robotics-becomes-the-worlds-highest-valued-ai-chip-unicorn/ 